\title{
Non-invasive monitoring of ovarian function in Asian elephants (Elephas maximus) by measurement of urinary $5 \beta$-pregnanetriol
}

\author{
C. A. Niemuller ${ }^{1 *}$, H. J. Shaw ${ }^{1}$ and J. K. Hodges ${ }^{2}$ \\ ${ }^{1}$ Institute of Zoology, Zoological Society of London, Regent's Park, London, NWI 4RY, UK, \\ and ${ }^{2}$ Division of Reproductive Biology, German Primate Centre, Kellnerweg 4, D-3400, Göttingen,
}

Germany

\begin{abstract}
The development of an enzymeimmunoassay for $5 \beta$-pregnanetriol and its use for noninvasive monitoring of reproductive cycles in Asian elephants is described. Gas chromatography-mass spectrometry (GCMS) and high performance liquid chromatography (HPLC) confirmed the presence of $5 \beta$-pregnane-3 $\alpha, 17 \alpha, 20 \alpha / \beta$-triols as the two most abundant urinary progesterone metabolites. The assay developed used the antiserum anti$5 \beta$-pregnane- $17 \alpha, 20 \alpha$-diol-3 $\alpha-\gamma \mathrm{l}$ glucuronide but was designed to measure the free steroid in urine samples after hydrolysis and extraction. HPLC confirmed the presence of immunoreactive pregnanetriol in urine, but indicated that the measurement was nonspecific. Immunoreactive pregnanetriol concentrations were significantly correlated with the concentrations of both progesterone $(r=0.98, n=269, P<0.01)$ and $17 \alpha$-hydroxyprogesterone $(r=0.95, n=205, P<0.01)$, the metabolic precursor of pregnanetriol. The mean $\pm \mathrm{SEM}$ deviation of cycles as determined by measurements of plasma progesterone, $17 \alpha$ hydroxyprogesterone and urinary pregnanetriol, respectively, were $15.54 \pm 1.5(n=23$, where $n=$ number of cycles), $15.21 \pm 1.7(n=15)$ and $15.45 \pm 0.94$ weeks $(n=20)$. These results demonstrate that it is possible to monitor ovarian function in Asian elephants by the measurement of urinary immunoreactive pregnanetriol concentrations.
\end{abstract}

\section{Introduction}

The two species of elephant existing today (Elephas maximus and Loxodonta africana) are classified as endangered (CITES, 1992), with current estimated wild populations of 50000 and 500000 , respectively. For both species, habitat loss and poaching have been major factors contributing to the decline and fragmentation of the wild populations. At the same time, zoos and private reserves have become increasingly active in the development of management and breeding programmes for animals in captivity, although the establishment of conditions conducive to successful reproduction is often difficult.

During the last 10 years, hormonal methods for monitoring ovarian cycles in both Asian and African elephants have been described. Typically, the duration of an ovarian cycle is $14-16$ weeks and is characterized by an 8-10 week luteal phase and a 4-6 week interluteal or follicular phase, according to patterns of circulating concentrations of progesterone (Hess et al., 1983; Brannian et al., 1988; Plotka et al., 1988; Brown et al., 1991; Taya et al., 1991). Concentrations of oestradiol and of LH have also been measured in plasma, but concentrations are generally very low or results inconsistent between studies, and their secretion has not proved useful for indicating ovarian status (Hess et al., 1983; Brannian et al., 1988; Plotka et al., 1988; Mainka and

*Present address: RR I Cambridge, Ontario, N1R 5S2, Canada. Received II February 1993.
Lothrop, 1990; Brown et al., 1991; Taya et al., 1991; Gross et al., 1991).

Measurement of circulating concentrations of progesterone therefore provides the most reliable monitor of ovulatory cycles in elephants and as such are widely used in many zoological collections. Unfortunately, the dependence on assessing ovarian function by plasma hormone analysis has been a hindrance for those zoological collections in which collection of blood samples is not possible and cannot be used in studies monitoring the reproductive dynamics of wild animals. There is therefore a need to develop a non-invasive approach for endocrine reproductive assessment in elephants. On the basis of our limited knowledge of elephant ovarian physiology, this should be most feasible by the measurement of urinary progesterone metabolites.

There are no reports of the identity of urinary metabolites of progesterone in elephants. A recent attempt to monitor ovarian function by measuring unmetabolized progesterone in urine from Asiatic elephants was unsuccessful (Mainka and Lothrop, 1990). Although measurement of urinary pregnanediol glucuronide or $20 \alpha$-dihydroprogesterone immunoreactivity has provided valuable information on ovarian function in a variety of mammalian species (see, for example, Loskutoff et al., 1986; Kirkpatrick et al., 1990; Hindle et al., 1992; Hodges, 1992 for review), our own unpublished observations (J. Hindle and C. Niemuller) indicated that this did not hold true for Asian elephants. The aims of the present study were therefore to (i) identify the major urinary progesterone metabolite(s) in 
Asian elephants (ii) develop a microtitre plate enzymeimmunoassay for its determination and (iii) evaluate its use as a noninvasive method for monitoring reproduction in this species.

\section{Materials and Methods}

\section{Animals and sample collection}

Where possible, matched blood and urine samples were collected once a week for I-3 years from II mature female elephants aged 12-25 years from four zoological collections. A 5-10 ml blood sample was collected from either the saphenous vein or an ear vein into heparinized tubes, centrifuged at $2000 \mathrm{~g}$ for $10 \mathrm{~min}$ immediately after collection, and the plasma stored at $-20^{\circ} \mathrm{C}$. Mid-stream urine samples were collected during the morning, divided into $5 \mathrm{ml}$ aliquots and stored frozen at $-20^{\circ} \mathrm{C}$.

Oestrous behaviour in the eight females that had access to males was recorded by the elephant keepers on the basis of increased interest by the bull and eventual copulation with the females. Three of the females monitored had no contact with males throughout the duration of the study. Of the eight females that had access to males, three were kept with the bull(s) daily but separated at night. The remaining five cows had continuous access to a bull except during the winter months. During this time, access to the male was restricted to daylight working hours and only for a cow in the latter half of the follicular phase as predicted by analysis of plasma progesterone. As soon as concentrations of plasma progesterone began to rise, the cow had no further contact with the bull.

\section{Creatinine determination}

All urine samples were analysed for creatinine concentration after the initial thawing by the method of Hodges and Green (1989) and as previously validated for elephants by Ramsey et al. (1981) and Poole et al. (1984), to correct for variations in glomerular filtration rate of urine. The assay sensitivity was approximately $0.1 \mathrm{mg} \mathrm{ml}^{-1}$ and the intra- and interassay coefficients of variation were 9.3 and $8.8 \%$, respectively $(n=30)$. Urinary creatinine concentration ranged from below detection (samples excluded) to approximately $2 \mathrm{mg} \mathrm{ml}^{-1}$, with a mean of $0.6 \mathrm{mg} \mathrm{ml}^{-1}$.

\section{Gas chromatography mass spectrometry}

Ten urine samples (each $20 \mathrm{ml}$ ) from three pregnant cows and from seven nonpregnant cows in the mid-luteal $(n=4)$, and follicular $(n=3)$ phase were prepared for gas chromatography mass spectrometry (GCMS) analysis by the method of Shackleton et al. (1976). In brief, samples were extracted using a Sep-pack C18 column (Waters, Division of Millipore, UK Ltd, Watford), hydrolysed using sodium acetate hydrolysis buffer $(\mathrm{pH}=5)$ and $25 \mathrm{mg} \beta$-glucuronidase-aryl sulfatase (Sigma, Poole, Dorset, sulfatase activity: $12.5 \mathrm{U} \mathrm{mg}^{-1}$ solid, $\beta$-glucuronidase activity: $1000 \mathrm{U} \mathrm{mg}^{-1}$ solid) and then re-extracted via Sep-pack before being dried down on a rotary evaporator. Samples were reconstituted in a 4:1 (v:v) cyclo-hexane:ethanol solution and separated into three distinct fractions with Sephadex LH-20 (Pharmacia, St Albans, Herts.). The fractions were dried down, reconstituted in ethanol and derivatized with methoxyamine hydrochloride and trimethylsilylimadazole. The final sample was reconstituted in $500 \mu \mathrm{l}$ cyclohexane of which $I \mu \mathrm{l}$ was injected into the gas chromatography mass spectrometer.

Mass spectrometer (MS) profiles thus obtained were scanned and identification of unknown peaks attempted initially by retention times and by computer MS library search (Shackleton et al., 1980). Peaks from gas chromatography (GC) were compared with reference templates and re-run through the GC with straight chain alkanes to determine methylene units for further identification. This was followed wherever possible by coinjection of the unknown peaks with steroid reference standards to determine change in peak height and provide further confirmation of the identity of the steroid metabolite.

\section{Preparation of $\left.{ }^{3} \mathrm{H}\right]$ pregnanetriol}

As $\left[{ }^{3} \mathrm{H}\right]$ pregnanetriols were not commercially available, a $\left[{ }^{3} \mathrm{H}\right]$-labelled form of one of the isomers was prepared in our laboratory by the enzymatic reduction of $\left[{ }^{3} \mathrm{H}\right] 17 \alpha$-hydroxy- $5 \beta$ pregnane-3 $\alpha, 20 \alpha$-diol (Amersham, Buckinghamshire) with $3 \alpha-$ hydroxysteroid dehydrogenase and NADH (method provided by A. P. Scott; Ministry of Agriculture, Fisheries and Food (MAFF), Fisheries Laboratory, Lowestoft). The reagents were incubated for $2 \mathrm{~h}$ at room temperature, and the products ether extracted before thin layer chromatography. Preliminary identification of $5 \beta$-pregnane- $3 \alpha, 17 \alpha, 20 \alpha$-triol as the predominant labelled product was confirmed by recrystallization of the major radioactive peak and pure standard to constant specific activity (SA). The tracer thus prepared had an activity of $8.8 \mu \mathrm{Ci} \mathrm{ml}^{-1}$ and was subsequently used to indicate steroid retention time on HPLC.

\section{HPLC}

Unconjugated neutral steroids were separated using HPLC. Sample preparation was done according to the method of Hindle et al. (1992). Urine samples ( $1 \mathrm{ml}$ ) were adjusted to $\mathrm{pH} 5$ with hydrolysis buffer and hydrolysed overnight with $1000 \mathrm{FU}$ $(50 \mu \mathrm{l})^{-1}$ of hydrolysis enzyme (Sigma, sulfatase activity: $4500 \mathrm{U} \mathrm{ml}^{-1}, \beta$-glucuronidase activity: $100000 \mathrm{U} \mathrm{ml}^{-1}$ ). Since conjugated pregnanetriol was not available, efficiency of hydrolysis was monitored by the addition of $\left[{ }^{3} \mathrm{H}\right]$ pregnanediol glucuronide $\left(\left[{ }^{3} \mathrm{H}\right] \mathrm{PdG}\right)$ to pooled urine samples monitored separately. Samples were adjusted to $\mathrm{pH}=7$ with $3 \mathrm{~mol} \mathrm{NaOH}^{-1}$ and extracted with $5 \mathrm{ml}$ distilled diethyl ether. Before extraction $\left[{ }^{3} \mathrm{H}\right]$ steroids (progesterone, 20 $\alpha$-dihydroprogesterone, $17 \alpha$ hydroxyprogesterone and pregnanetriol) were added to the sample as reference standards and to monitor extraction efficiency. The ether was dried under nitrogen and samples were reconstituted in $0.2 \mathrm{ml}$ of double distilled water:acetonitrile $(70: 30 \mathrm{v}: \mathrm{v})$.

The progesterone metabolites were separated using a Novapak RP C- 18 column $(3.9 \times 150 \mathrm{~mm}, 5 \mu \mathrm{m}$ particle size; Waters $)$ and an isocratic solvent system of 30:70 acetonitrile:water at a flow rate of $2 \mathrm{ml} \mathrm{min}{ }^{-1}$ (B. Junemann, unpublished). Fractions ( $1 \mathrm{ml}$ ) were collected for $36 \mathrm{~min}$, dried and reconstituted in Downloaded from Bioscientifica.com at 04/26/2023 10:27:47AM 
assay buffer. Mean recoveries for the four tracers were between 71 and $78 \%(n=14)$. The overall efficiency of the procedure, including hydrolysis and extraction, was $68.8 \pm 4.2 \%(n=14)$ based on the recovery of $\left[{ }^{3} \mathrm{H}\right]$ pregnanediol.

\section{Urinary hormone assays}

Sample preparation. Urine samples were hydrolysed and extracted before assay. An aliquot of $250 \mu \mathrm{l}$ of urine was incubated overnight at $37^{\circ} \mathrm{C}$ with $250 \mathrm{FU}(50 \mu \mathrm{l})^{-1}$ of hydrolysis enzyme (Sigma, sulfatase activity: $4500 \mathrm{U} \mathrm{ml}^{-1}, \beta$-glucuronidase activity: $100000 \mathrm{U} \mathrm{ml}^{-1}$ ) and $250 \mu \mathrm{l}$ of hydrolysis buffer. Hydrolysis efficiencies were determined by adding in triplicate tracer amounts of $\left[{ }^{3} \mathrm{H}\right]$ oestrone sulfate and oestrone glucuronide to urine pools $(250 \mu \mathrm{l})$ before hydrolysis. Amounts of unconjugated steroid recovered were $81.1 \pm 6.1 \%$ and $84.3 \pm 3.2 \%$ (mean $\pm \mathrm{SEM}, n=30$ ), respectively. The $\mathrm{pH}$ was readjusted to 7 with $3 \mathrm{~mol} \mathrm{NaOH}{ }^{-1}$ and samples were extracted with diethyl ether and reconstituted in assay buffer. Procedural losses during extraction were monitored by the addition of tracer amounts of $\left.{ }^{3} \mathrm{H}\right] 17 \alpha$-hydroxyprogesterone to each sample. Individual recoveries were used to correct for losses when calculating the final hormone concentration. The overall mean \pm SEM extraction was $89.1 \pm 2.1 \%(n=200)$.

Pregnanetriol. Immunoreactive $5 \beta$-pregnanetriol was measured using a microtitre plate EIA method similar to that described by Hindle et al. (1992). The assay used the antiserum $5 \beta$-pregnane-17,20a-diol-3 $\alpha-\gamma l$ glucuronide which was raised in rabbit against the immunogenic complex of $5 \beta$-pregnane$17,20 \alpha$ diol- $3 \alpha-\gamma$ l glucuronide coupled to BSA (Samarajeewa and Kellie, 1985). The enzyme label, provided by E. Möstl (Institut für Biochemie, Veterinärmedizinische Universität, Vienna), was prepared by conjugating 4-pregnene-17 $\alpha, 20 \alpha$ diol-3-one-carboxymethyloxime to horse radish peroxidase via the mixed acid anhydride procedure of Lieberman et al. (1959). The antiserum, which crossreacted $62.5 \%$ with the free steroid as determined by radioimmunoassay (Samarajeewa and Kellie, 1985), was stored in aliquots of $1: 1000$ in Tris buffer at $-20^{\circ} \mathrm{C}$ while the enzyme label was stored in glycerol $(1: 1 \mathrm{v}: \mathrm{v})$ also at $-20^{\circ} \mathrm{C}$.

Microtitre plates (Nunc Immuno 1: Gibco Ltd, Paisley) were coated overnight with sheep anti-rabbit IgG $(1 \mu \mathrm{l}$ per well). The plates were emptied by inversion, filled with Tris buffer ( $20 \mathrm{nmol} \mathrm{l}^{-1} ; 0.25 \mathrm{ml}$ per well) containing $0.1 \%$ sodium azide and stored at $4^{\circ} \mathrm{C}$ until needed. Just before use, the plates were emptied, rinsed with a $0.005 \%$ Tween solution and blotted dry. Standard ( $5 \beta$-pregnane $3 \alpha, 17 \alpha, 20 \alpha$-triol, Sigma, Poole) was double diluted in Tris buffer over a range of $156 \mathrm{pg} \mathrm{ml}^{-1}-10 \mathrm{ng}$ $\mathrm{ml}^{-1}\left(7.8-500 \mathrm{pg}(50 \mu \mathrm{l})^{-1}\right)$ and $0.05 \mathrm{ml}$ aliquots dispensed in duplicate. Samples were diluted in Tris assay buffer and added in duplicate $(0.05 \mathrm{ml})$. Antiserum (1:160 000) and label ( $1: 30000)$ were added to all wells except the blanks. Plates were covered and incubated overnight in the dark at $4^{\circ} \mathrm{C}$.

After incubation, plates were emptied by inversion, washed with $0.005 \%$ Tween solution and tapped dry. Enzyme substrate was prepared immediately before use by adding $0.025 \mathrm{ml}$ hydrogen peroxide solution $\left(30 \%, 4 \mathrm{~mol} \mathrm{l^{-1 }}, \mathrm{BDH}\right)$ to $100 \mathrm{mg}$ O-phenylenediamine; (1,2, benzenediamine; Sigma) in $28 \mathrm{ml}$ of

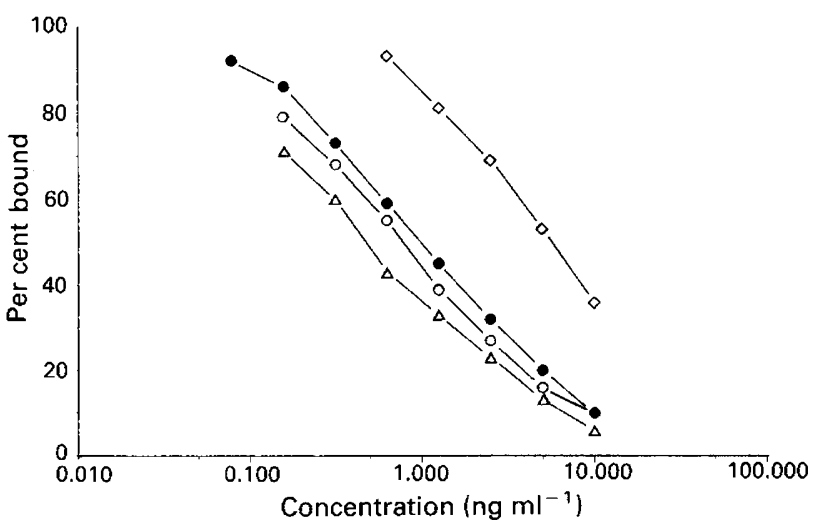

Fig. 1. Binding inhibition curves demonstrating parallelism in serially diluted Asian elephant urine pool samples from the mid-luteal $(\triangle)$ and follicular phase $(\diamond)$ as well as human urine from late pregnancy $(\bigcirc)$; pregnanetriol standard $(\mathbf{O})$.

a citric acid substrate buffer $\left(0.1 \mathrm{~mol}\right.$ citric acid monohydrate $\mathrm{I}^{-1}$; $\mathrm{pH}=5$ ). A volume of $0.25 \mathrm{ml}$ was added to each well; plates were incubated in the dark at $4^{\circ} \mathrm{C}$ for $45 \mathrm{~min}$ and the reaction was stopped by the addition of $0.05 \mathrm{ml}$ of sulfuric acid $\left(3 \mathrm{~mol} \mathrm{l}^{-1}\right)$. Absorbance was measured at $492 \mathrm{~nm}$ (with a reference filter of dual wavelength at $620 \mathrm{~nm}$ ) on an automatic plate reader (Dynatech MR 700, Dynatech Laboratories Ltd, Billinghurst). The amount of immunoreactive pregnanetriol in each well was read from a standard curve constructed by plotting the percentage of sample bound against the amount of standard added.

Pregnanetriol EIA validation. The sensitivity of the assay as determined at $90 \%$ binding was $8.5 \mathrm{pg}$ per well (170 $\left.\mathrm{pg} \mathrm{ml}^{-1}\right)$. Serial dilutions of elephant urine collected during the mid-luteal and follicular phase and of human late pregnancy urine (a known source of high concentrations of pregnanetriol) gave displacement curves parallel to the $5 \beta$-pregnanetriol standard (Fig. 1). The accuracy of the assay, determined by recovery of unlabelled $5 \beta$-pregnane- $3 \alpha, 17 \alpha, 20 \alpha$-triol added to elephant urine pools containing low concentrations of endogenous hormone was $98.7 \% \pm 1.1 \%(n=10)$. The interassay $\mathrm{CV}$ for repeated determination of elephant urine pool containing high and low concentrations of pregnanetriol was 10.8 and $5.6 \%$ $(n=30)$, respectively, while the intra-assay $\mathrm{CV}$ was $7.8 \%$ $(n=30)$. Steroids showing crossreactivity determined at $50 \%$ inhibition of binding, were $5 \alpha$-pregnane- $3 \beta, 17,20 \alpha$-triol (109\%), $5 \beta$-pregnane-3 $\alpha, 6 \alpha, 17 \alpha, 20 \alpha$-tetrol (189\%), $5 \beta$-pregnane$3 \alpha, 6 \alpha, 17 \alpha, 20 \beta$-tetrol (113\%), $5 \alpha$-pregnane $3 \beta, 17 \alpha, 20 \beta$-triol (106\%), $5 \beta$-pregnane-3 $\alpha, 17 \beta, 20 \beta$-triol $(2.9 \%)$, progesterone (1.45\%), $5 \beta$-pregnanediol (1.1\%). All of the other C21, C19 and C18 steroids tested crossreacted less than $1 \%$. Specificity of measurement of pregnanetriol in Asian elephant urine was determined by co-chromatography on HPLC. The presence of pregnanetriol immunoreactivity co-eluting with the $5 \beta$ pregnanetriol tracer (Fig. 2) confirmed that the assay could detect pregnanetriol in urine from Asian elephants. However, the presence of large amounts of immunoreactivity in fractions preceding the peak of $\left.{ }^{3} \mathrm{H}\right]$ pregnanetriol indicated that the measurement of pregnanetriol was not specific. The values 


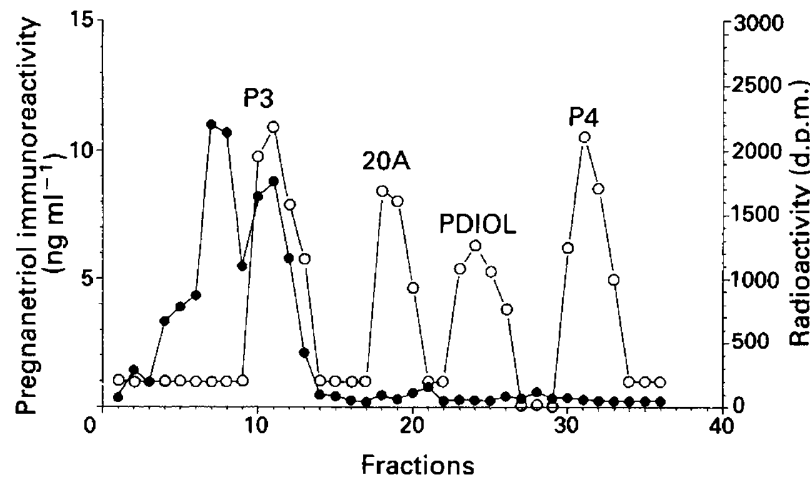

Fig. 2. Co-chromatography profiles from HPLC of immunoreactive progesterone metabolites in Asian elephant urine. The elution profile (O) of pregnanetriol immunoreactivity in hydrolysed and extracted urine is compared with that of $\left[{ }^{3} \mathrm{H}\right]$-labelled pregnanetriol (P3), 20adihydroprogesterone (20A), pregnanediol (PDIOL) and progesterone (P4) (O).

reported here are therefore expressed as pregnanetriol immunoreactivity.

20a-Dihydroprogesterone ELA. The assay was as described by Hindle et al. (1992). Immunoreactive 20a-dihydroprogesterone was measured in fractions collected from the HPLC. The assay using an anti-4-pregnene-20 $\alpha$-ol-3-one-carboxymethyloxime antiserum and enzyme conjugate of horse radish peroxidase conjugated to $20 \alpha$-dihydroprogesterone (provided by E. Möstl) showed crossreactivities with $5 \beta$-pregnane-20 $\alpha$-ol-3-one (11.9\%), $5 \beta$-pregnene $3 \alpha$-ol-20-one $(0.92 \%)$, $5 \beta$-pregnane- $3 \alpha-20 \alpha$ diol $(0.57 \%)$, progesterone $(0.52 \%)$, pregnenolone $(<0.1 \%)$ and $5 \beta$ pregnane-3 $\alpha, 17 \alpha, 20 \alpha$-triol $(<0.01 \%)$. The assay sensitivity as determined at $90 \%$ binding was $150 \mathrm{pg} \mathrm{ml}^{-1}$. The intra-assay $\mathrm{CV}$ was $8.4 \%(n=30)$, whereas the interassay $\mathrm{CV}$ was 12.1 and $16.1 \%(n=15)$ for high and low value quality control pools, respectively.

\section{Assays of plasma hormone}

Progesterone. Progesterone was measured by radioimmunoassay as initially described by Shaw et al. (1989) with modifications. The assay used $1,2,6,7-\left[{ }^{3} \mathrm{H}\right]$ progesterone (Amersham) and sheep anti-progesterone $11 \alpha$-hemisuccinate-ovalbumin (from J. Foulkes, MAFF, Shinfield, Reading) as antiserum which showed the following crossreactivities: $11 \alpha$-hydroxyprogesterone $(29.8 \%), 11 \beta$-hydroxyprogesterone (16.5\%), $5 \beta$-pregnanedione $(16.1 \%), 5 \alpha$-pregnanedione $(2.63 \%)$ and less than $0.1 \%$ with all other steroids tested. Samples $(500 \mu \mathrm{l})$ were extracted with petroleum ether (recovery $83.6 \pm 2.3 \%, n=200$ ) and reconstituted in assay buffer. The sensitivity of the assay at $90 \%$ binding was $20 \mathrm{pg} \mathrm{ml}^{-1}$; intra- and interassay $\mathrm{CV}$ s were $8.9 \%$ and $10.7 \%$, respectively. Serial dilutions of extracted elephant plasma gave displacement curves parallel to the progesterone standard. The accuracy of the assay determined by the mean \pm SEM recovery of unlabelled progesterone added to extracted plasma pools of low endogenous hormone was $99.4 \pm 2.5 \%$.

17a-Hydroxyprogesterone. The measurement of $17 \alpha$-hydroxyprogesterone in plasma and HPLC samples followed the same protocol as used for the progesterone radioimmunoassay. The assay used $1,2,6,7-\left[^{3} \mathrm{H}\right] 17 \alpha$-hydroxyprogesterone (Amersham) with an anti-sheep-17-hydroxyprogesterone-3carboxymethyloxime antiserum (Steranti, St Albans). The antiserum crossreacted with progesterone $(2.2 \%)$ and $5 \alpha$ pregnanedione $(1.1 \%)$ as determined by Steranti. Other C21. and $\mathrm{C}_{19}$ steroids tested crossreacted less than $1 \%$. Samples $(500 \mu \mathrm{l})$ were extracted with petroleum ether (recovery $87.6 \pm 3.1 \%, n=200$ ) and reconstituted in assay buffer. The sensitivity of the assay based on $90 \%$ binding was $20 \mathrm{pg} \mathrm{ml}^{-1}$, while intra- and interassay CVs were 6.3 and $9.7 \%$, respectively. Serial dilutions of samples extracted from plasma of pregnant and mid-luteal phase elephants gave displacement curves parallel to the $17 \alpha$-hydroxyprogesterone standard. The accuracy of the assay determined by the mean \pm SEM recovery of unlabelled $17 \alpha$-hydroxyprogesterone $\left(10-160 \mathrm{pg} \mathrm{ml}^{-1}\right)$ added to extracted plasma pools of low endogenous hormone was $101.7 \pm 1.4 \%$.

\section{Analysis of data}

Stages of the ovarian cycle. The definition for the luteal and follicular stages of the elephant reproductive cycles based on analysis of plasma hormones for this study was modelled after the definition originally described by Plotka et al. (1988). For both progesterone and $17 \alpha$-hydroxyprogesterone, the onset of the luteal phase of the cycle was defined as the first point (after the respective plasma concentrations fell below $200 \mathrm{pg} \mathrm{ml}^{-1}$ ) that increased by $50 \mathrm{pg}$ and remained high for at least two weeks; the end of the luteal phase was defined as the first of two consecutive values within $50 \mathrm{pg}$ that were less than $200 \mathrm{pg}$ and at least $50 \mathrm{pg}$ lower than the preceding value. The composite data presented were therefore aligned to the onset of the luteal phase (week 1) according to this definition.

Similarly, according to urinary pregnanetriol concentrations, the onset of the luteal phase was defined as the first point after a fall in values below $200 \mathrm{ng} \mathrm{mg}^{-1}$ creatinine which increased by $50 \mathrm{ng} \mathrm{mg}^{-1}$ creatinine and remained high for at least two weeks. Similarly, the end of the luteal phase was taken as the first of two consecutive values within $50 \mathrm{ng} \mathrm{mg}^{-1}$ creatinine, which were less than $200 \mathrm{ng} \mathrm{mg}^{-1}$ creatinine and at least $50 \mathrm{ng} \mathrm{mg}^{-1}$ creatinine lower than the preceding value.

The duration of the ovarian cycle was determined as the interval between the onset of two successive luteal phases as defined separately for each hormone measured.

\section{Statistical analysis}

Statistical analysis was carried out by standard analyses of mean and SEM and Student's $t$ test as appropriate.

\section{Results}

According to the mass spectra obtained, the silyl ether derivatives of $5 \beta$-pregnanetriol (as described by Quilliam and Westmore, 1980) were the most abundant of the progesterone metabolites successfully identified. $5 \beta$-Pregnane-3 $3,17 \alpha 20 \alpha / \beta$ triols were present in every urine sample analysed from Downloaded from Bioscientifica.com at 04/26/2023 10:27:47AM 
Table 1. Summary of results of gas chromatography-mass spectrometry of urine from Asian elephants

\begin{tabular}{|c|c|c|}
\hline $\begin{array}{l}\text { Reproductive } \\
\text { state }\end{array}$ & $\begin{array}{l}\text { Identified steroid } \\
\text { metabolite }\end{array}$ & Incidence \\
\hline $\begin{array}{l}\text { Follicular } \\
(n=3)\end{array}$ & $\begin{array}{l}11 \beta \text {-hydroxyandrosterone/aeticholanolone } \\
\text { No detectable pregnanetriols }\end{array}$ & $\begin{array}{l}1 \\
3\end{array}$ \\
\hline $\begin{array}{l}\text { Mid-luteal } \\
(n=4)\end{array}$ & $\begin{array}{l}5 \beta \text {-pregnane- } 3 \alpha, 17 \alpha, 20 \alpha \text {-triol } \\
5 \beta \text {-pregnane- } 3 \alpha, 17 \alpha, 20 \beta \text {-triol } \\
5 \beta \text {-pregnane- } 3 \alpha, 6 \alpha, 20 \alpha \text {-triol } \\
5 \alpha \text {-pregnane- } 3 \alpha, 11 \beta, 20 \alpha \text {-triol } \\
5 \alpha \text {-pregnane- } 3 \beta, 17,20 \alpha \text {-triol } \\
3 \alpha, 20 \alpha \text { dihydroxy-5 } \beta \text {-pregnan-11-one } \\
11 \beta \text {-hydroxyandrosterone/aeticholanolone }\end{array}$ & $\begin{array}{l}4 \\
4 \\
2 \\
1 \\
1 \\
1 \\
1\end{array}$ \\
\hline $\begin{array}{l}\text { Pregnancy } \\
(n=3)\end{array}$ & 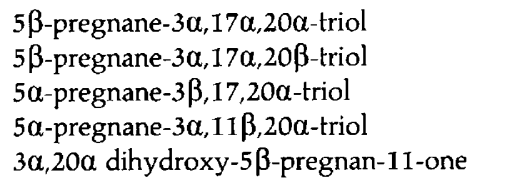 & $\begin{array}{l}3 \\
3 \\
1 \\
1 \\
2\end{array}$ \\
\hline
\end{tabular}

pregnant Asian elephants and those at the mid-luteal phase (Table 1). Quantitatively, these two steroid metabolites were also the most abundant forms of pregnanetriol present (data not shown). It was not possible to detect any pregnanetriol in urine from the follicular phase, and progesterone, pregnanediol and 20a-dihydroprogesterone were not detected in any samples.

The results of HPLC analysis of a sample of hydrolysed and extracted urine from Asian elephants at the mid-luteal phase are shown (Fig. 2). Immunoreactivity co-eluting with the $\left[{ }^{3} \mathrm{H}\right]$ pregnanetriol marker was found in all samples tested $(n=6)$, thus indicating the presence of immunoassayable pregnanetriol in urine of Asian elephants at the luteal phase. As indicated earlier, relatively large amounts of additional immunoreactivity not co-eluting with the $\left[{ }^{3} \mathrm{H}\right]$ pregnanetriol label was also present in fractions $4-9$ in all samples analysed $(n=6)$. In contrast, progesterone, 20 $\alpha$-dihydroprogesterone and $17 \alpha$ hydroxyprogesterone were not detectable in HPLC fractions by their specific assays at the volumes and dilutions used.

The profile of urinary pregnanetriol immunoreactivity in relation to that of circulating progesterone concentrations during three consecutive ovarian cycles in one elephant is shown (Fig. 3). The urinary measurements revealed a cyclic pattern of excretion in which the luteal and interluteal periods, as determined by intervals of high and low circulating progesterone concentrations, could be clearly distinguished. In this animal, maximum pregnanetriol concentrations at the luteal phase were between 300 and $750 \mathrm{ng} \mathrm{mg}^{-1}$ creatinine, approximately fivefold greater than those of the corresponding interluteal period. There is a close temporal relationship between the defined rise in plasma progesterone and urinary pregnanetriol following predicted ovulation in each of the three cycles illustrated.

Composite profiles of the mean and SEM of plasma concentrations of progesterone ( $n=11$ animals, $n=23$ cycles) and urinary concentrations of pregnanetriol $(n=8$ animals, $n=20$ cycles) throughout the ovarian cycle in Asian elephants are shown (Fig. 4). Corresponding data for plasma 17ahydroxyprogesterone, the major circulating precursor for preg-
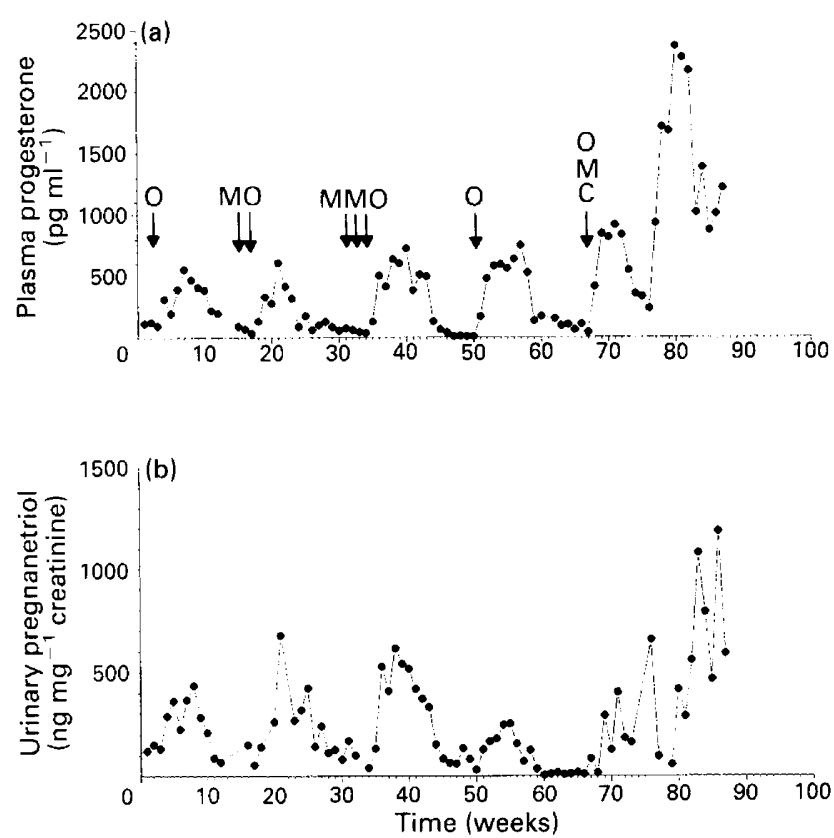

Fig. 3. Representative reproductive profile of weekly (a) plasma progesterone and (b) urinary pregnanetriol concentrations for one female Asian elephant through four consecutive reproductive cycles and into early pregnancy. (O: predicted ovulation; $\mathrm{M}$ : mating; $\mathrm{C}$ : conception).

nanetriol (Axelrod and Goldzieher, 1960), are also shown from 15 of these cycles ( $n=8$ animals). All data were aligned to the rise in plasma progesterone reflecting the start of the luteal phase. The overall duration of the oestrous cycle (mean \pm SEM) calculated from the interval between successive luteal phases was $15.54 \pm 1.5(n=23), 15.21 \pm 1.7(n=15)$ and $15.45 \pm$ $0.94(n=20)$ weeks, based on measurements of plasma progesterone, $17 \alpha$-hydroxyprogesterone and urinary pregnanetriol, respectively. Immunoreactive pregnanetriol concentrations were significantly corretated with the concentrations of both progesterone $(r=0.98, n=269$ cycles, $P<0.01)$ 

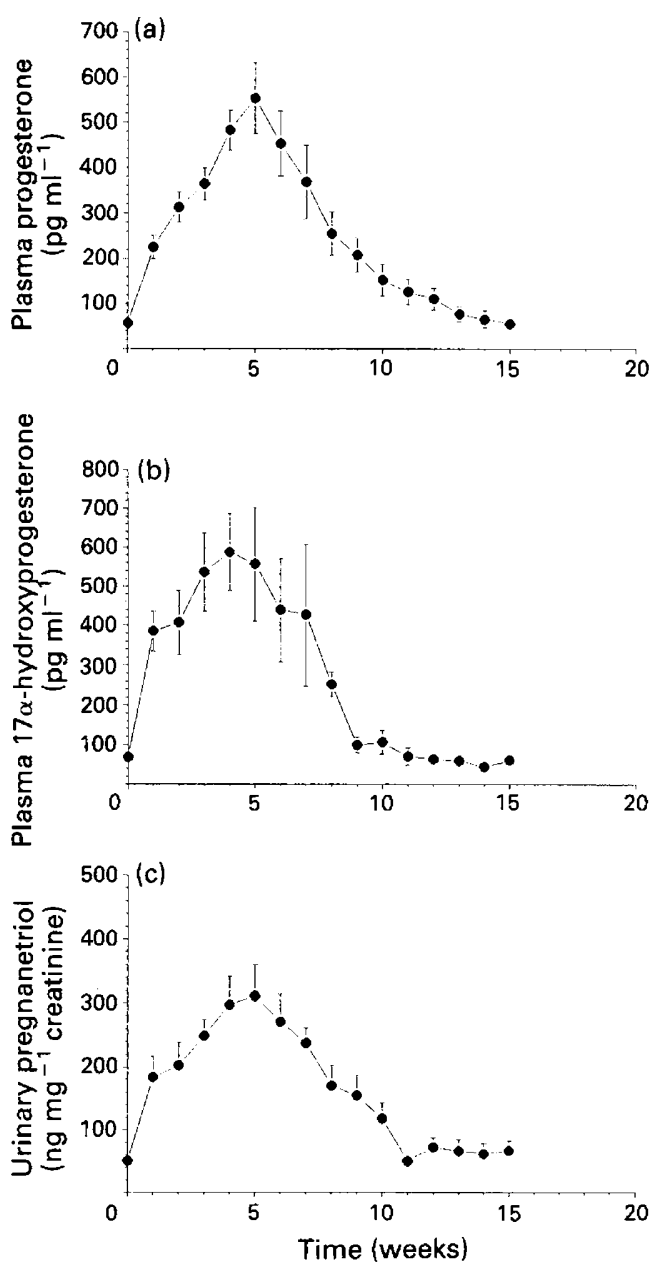

Fig. 4. Mean ( \pm SEM) profiles of weekly concentrations of (a) progesterone, (b) 17 $a$-hydroxyprogesterone and (c) pregnanetriol samples for Asian elephants $(n=11)$ representing one reproductive cycle). All data were aligned to the elevation in plasma or urinary steroid concentrations (week 1) until the following week 1 .

and 17 $\alpha$-hydroxyprogesterone $\langle r=0.95, n=205$ cycles, $P<0.01$ ) throughout the ovarian cycle. Plasma concentrations of $17 \alpha$-hydroxyprogesterone were also significantly correlated with circulating concentrations of progesterone during the ovarian cycle $(r=0.93, n=205$ cycles, $P<0.01)$.

The data show clear cyclic patterns of pregnanetriol excretion, with values increasing from an overall mean of $45 \mathrm{ng} \mathrm{mg}^{-1}$ creatinine (range $5-172 \mathrm{ng} \mathrm{mg}^{-1}$ creatinine) during the interluteal period to a mean of $237 \mathrm{ng} \mathrm{mg}^{-1}$ creatinine in the luteal phase (range $75-802 \mathrm{ng} \mathrm{mg}^{-1}$ creatinine). Although variability was seen in pregnanetriol values, both between cycles and between animals, the extent of this was not markedly different from that seen in measurements of plasma hormones (as evidenced by the size of the SE bars in Fig. 3). Most importantly the trend of high urinary pregnanetriol concentrations throughout the interluteal period was maintained in all profiles and of the 20 cycles with matching progesterone and pregnanetriol data, defined rises in both hormones occurred on the same date 18 times $(90 \%)$. In the remaining two cycles, the rises were separated by one week (for example, one sample apart).
Table 2. Relationship between predicted oestrus and mating events in six Asian elephants from one zoo from January 1989 - November 1991

\begin{tabular}{|c|c|c|c|c|}
\hline \multirow[b]{2}{*}{$\begin{array}{l}\text { Total } \\
\text { number of } \\
\text { cycles }\end{array}$} & \multirow{2}{*}{$\begin{array}{l}\text { Mating } \\
\text { matching } \\
\text { predicted } \\
\text { oestrus } \\
(\%)\end{array}$} & \multicolumn{2}{|c|}{$\begin{array}{l}\text { No mating with } \\
\text { predicted oestrus }\end{array}$} & \multirow[b]{2}{*}{$\begin{array}{l}\text { Resulting } \\
\text { pregnancy }\end{array}$} \\
\hline & & $\begin{array}{c}\text { Wrong } \\
\text { time } \\
(\%)\end{array}$ & $\begin{array}{c}\text { No } \\
\text { mating } \\
(\%)\end{array}$ & \\
\hline 8 & $4(50)$ & $1(12.5)$ & $3(37.5)$ & 1 \\
\hline 11 & $4(36.4)$ & $4(36.4)$ & $3(27.3)$ & 0 \\
\hline 6 & $3(50)$ & $I(16.7)$ & $2(33.3)$ & 0 \\
\hline 8 & $3(37.5)$ & $1(12.5)$ & $4(50)$ & 0 \\
\hline 8 & $2(25)$ & $3(37.5)$ & $3(37.5)$ & 2 \\
\hline $4^{*}$ & I (25) & $0 \quad(0)$ & $3(75)$ & 0 \\
\hline 45 & $17(37.8)$ & $10(22.2)$ & $18(40)$ & 3 \\
\hline
\end{tabular}

*This cow completed a full term pregnancy in July of 1990.

In those cycles in which mating did occur (Fig. 3), only during the last (conception) cycle did mating correspond to the time of predicted ovulation resulting in pregnancy. In all of the other cases, mating either did not occur at all, or it occurred at least a week before the time of expected ovulation and did not result in conception. Furthermore, the apparent asynchrony between behavioural and endocrine (physiological) events was not confined to this individual, but was seen in all six adult females in the group to which she belonged (Table 2). The data were collected for 34 months and indicated that, out of a total of 45 ovarian (presumed ovulatory) cycles from six adult cows, mating coincided with the time of predicted ovulation in only $17(37.8 \%)$ cases. In the remaining $62.2 \%$ of the cycles, mating either did not occur $(40 \%)$ or occurred at a time separated from presumed ovulation $(22.2 \%)$. Of the 17 cycles in which mating appeared to coincide with ovulation, three resulted in conception (17.6\%). No pregnancy occurred from the mis-timed matings.

\section{Discussion}

This study has shown that $5 \beta$-pregnanetriol is a major urinary progesterone metabolite in Asian elephants. The establishment of an enzymeimmunoassay for the measurement of immunoreactive pregnanetriol has enabled the first description of the pattern of excretion of urinary progesterone metabolites throughout the ovarian cycle. The results suggest that measurement of pregnanetriol should provide a useful non-invasive method for monitoring reproductive status in this species.

The initial GCMS findings of relatively high concentrations of $5 \beta$-pregnanetriol in urine of female Asian elephants during various reproductive states was unusual, but may explain the previous lack of success in attempting to monitor reproductive cycles with more commonly measured progesterone metabolites such as $20 \alpha$-dihydroprogesterone and pregnanediol glucuronide. Measurement of urinary pregnanediol or $20 \alpha$-dihydroprogesterone have proved to be invaluable for monitoring reproductive 
status in a wide variety of species including black and white rhinos (Hindle et al., 1992), gorillas (Hodges and Green, 1989), giant pandas (Hodges et al., 1984), white-tailed deer (Knox et al., 1992), killer whales (Walker et al., 1988) and macaques (Monfort et al., 1986). In contrast, however, the immunoreactivity associated with these metabolites in Asian elephant urine is low and variable and their patterns of excretion do not correlate with ovarian events (J. Hindle and C. Niemuller, unpublished). Furthermore, in all samples analysed, neither progesterone nor

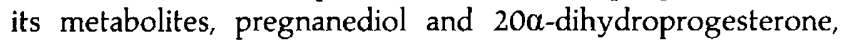
were detected by the GCMS procedures used. In an independent study, Mainka and Lothrop (1990) attempted but failed to measure urinary progesterone cycles in two Asian elephants, a finding consistent with the above results.

Pregnanetriol is a unique major urinary metabolite of $17 \alpha$ hydroxyprogesterone produced by reductions in ring $\mathrm{A}, \mathrm{C}-3$ and C-20 (Gower and Honour, 1984). Thus, the formation of pregnanetriol follows a separate pathway from that used in the production of $20 \alpha$-dihydroprogesterone and pregnanediol (Gower and Honour, 1984), for which $17 \alpha$-hydroxyprogesterone is not an obligatory intermediate (Axelrod and Goldzieher, 1960).

The measurement of pregnanetriol, originally discovered in the urine of two women with congenital adrenal hyperplasia (Butler and Marrian, 1937), is normally used as an indicator of adrenal hyperplasia rather than for monitoring ovarian function. Human ovaries, however, are known to be a source of its precursor, 17 $\alpha$-hydroxyprogesterone (Zander, 1958, Short and London, 1961) and measurement of pregnanetriol for determining ovarian function in women has been reported (for example Pickett et al., 1959; Fotherby, 1960; Pickett and Kellie, 1962).

The results reported here are of nonspecific measurements of unconjugated pregnanetriol immunoreactivity, as HPLC data clearly indicated the presence of other, more polar immunoreactive substances. These unidentified substances may even be quantitatively more important than pregnanetriol; however, their nature remains unknown. Although the antibody crossreacts extensively with other pregnanetriol isomers and with pregnanetetrols, all of which can be expected to elute from HPLC at positions similar to that of the unknown, their contribution to the immunoreactive profiles described cannot be determined.

The nature of the relationship between urinary pregnanetriol and plasma $17 \alpha$-hydroxyprogesterone prompted the initial measurements of $17 \alpha$-hydroxyprogesterone throughout the ovarian cycle of Asian elephants in this study. The significant correlation of circulating plasma concentration of $17 \alpha$ hydroxyprogesterone with progesterone suggests that the elephant ovary is a major source of this steroid and that urinary pregnanetriol concentrations are related to ovarian progesterone secretion. In other mammals, luteal phase $17 \alpha$-hydroxyprogesterone concentrations are much lower than progesterone concentrations. Furthermore, the significant correlation between pregnanetriol and both progesterone and $17 \alpha$-hydroxyprogesterone throughout the reproductive cycle provides additional evidence that pregnanetriol is a major urinary progesterone metabolite in elephants and that its pattern of excretion reflects ovarian function. The results presented here suggest that elephants may have significantly higher 17a-hydroxylase activity in both the ovary and the liver, which may explain why pregnanetriol is the major urinary progestagen metabolite.

The general features of the reproductive cycles described in this study were based upon reference measurements of circulating concentrations of plasma progesterone. Thus, the cyclic changes in the pattern of plasma progesterone concentrations indicated that the duration of the reproductive cycle of the 11 Asian elephants in this study ranged between 14 and 18 weeks, which matched with earlier descriptions (Hess et al., 1983; Plotka et al., 1988; Brown et al., 1991; Taya et al., 1991). Data presented from both the individual as well as the composite profiles revealed a cyclic pattern of pregnanetriol excretion highly correlated with circulating plasma progesterone and 17a-hydroxyprogesterone concentrations. Despite higher variability in urinary values as compared with plasma steroid concentrations, there was a clear fivefold increase in luteal phase values compared with interluteal phase values. Furthermore, $90 \%$ of the cycles analysed demonstrated an increase in pregnanetriol concentrations concurrent with the defined rise in plasma progesterone. Although plasma progesterone has to date been the most useful measurement in determining reproductive cycles, these results demonstrate that the measurement of pregnanetriol closely reflects progesterone secretion and corpus luteum function.

Although it is generally assumed that cyclic fluctuations in the concentrations of circulating progesterone (or its metabolites) reflect ovulatory cycles, there is no information on the elephant from which a cycle can be defined as endocrinologically or behaviourally normal. The results presented here indicate that in individuals from one particular group, only $25-50 \%$ of apparently 'normal' ovulatory cycles were associated with mating behaviour during the periovulatory period, despite access to bulls of proven fertility throughout this time. Furthermore, of the cycles in which mating did occur at the time of expected ovulation, less than $20 \%$ resulted in conception. In domestic species such as cows, horses, goats and sheep, conception rate per ovulatory event is higher, varying between 40 and 75\% (Bristol, 1986; McDonald, 1986; Smith, M. C., 1986; Smith, R. D., 1986). Data collected by researchers on wild African elephants in Amboseli National Park, Kenya, have noted a conception rate of approximately $75 \%$ (Moss, 1983). At this time, the reason for the high percentage of non-fertile cycles in the captive elephant population is unclear. Our data demonstrate that in only a small proportion of cycles does mating occur at the time of presumed ovulation. This behavioural/physiological imbalance may be related to the highly variable pattern of oestrogen secretion during the cycle and the inability in most studies to describe a clear preovulatory increase in oestrogens (Hess et al., 1983; Mainka and Lothrop, 1990; Brown et al., 1991; Taya et al, 1991). Furthermore, with the exception of the studies of Hess et al. (1983) and Mainka and Lothrop (1990), the above studies lacked the matching behavioural data for their endocrinological descriptions of the elephant reproductive cycle. These two studies indicated that the prevalence of non-fertile cycles in the present study group of cows was not an isolated event. Mainka and Lothrop (1990) described flehmen but not mating events of a bull towards a cow (who did not conceive) through five complete cycles and comment on three mating times of February, July and October in a second cow before conception occurred. Likewise, Hess 
et al. (1983) described 15 reproductive cycles divided between six cows, from which only two conceptions occurred. The reason for the apparent infertility is not understood.

The incidence of asynchronous mating with respect to presumed ovulation observed in this study does not appear to have been described before. The lack of mating or mistiming of mating may have been overestimated as animals were not constantly observed over $24 \mathrm{~h}$, thus matings occurring at night would not have been observed. The most important external cue received by the male from the female signifying onset of oestrus appears to be smell as determined by the flehmen responses (Jainudeen et al., 1971; Hess et al., 1983). Miscueing of these pheromonal signals on the part of the female may be another reason for mis-timed mating events. There may be a link between the timing of ovulation and miscueing of pheromonal signals, which might explain the asynchronous mating events.

In summary, this paper has identified $5 \beta$-pregnanetriol as a major urinary progesterone metabolite in Asian elephants and described its measurement throughout the ovarian cycle of this species. Its measurement in urine should not only enable routine, non-invasive monitoring of reproductive cycles in captivity, but also provide potential application towards assessing reproductive status in wild Asian elephants.

The authors are grateful to P. Samarajeewa, Department of Biochemistry, UCL for the donation of the pregnanetriol-glucuronide antibody, E. Möstl, Institut für Biochemie, Veterinärmedizinische Universität, Vienna, for the enzyme labels and S. Scott (MAFF) for $\left[{ }^{3} \mathrm{H}\right] 17$-hydroxy- $5 \beta$-pregnane-3 $\alpha, 20 a$-diol. They also owe thanks to J. Honour and M. Schneider, Middlesex Hospital for instruction and use of the GCMS and are indebted to M. Smith, B. Bliss and the keeping staff at Port Lympne Zoo, B. Harman and the elephant staff at London Zoo, C. Gray and staff at the African Lion Safari and D. Moore and C. Doyle and staff of Burnet Park Zoo for their invaluable assistance in sample collection. Finally, thanks go to J. Hindle and D. Green for advice and technical support. This project was supported by a private grant from Howlett's and Port Lympne Estates Ltd and from the University Federation of Animal Welfare.

\section{References}

Axelrod LR and Goldzieher JW (1960) The metabolism of 17ahydroxyprogesterone and its relation to congenital adrenal hyperplasia Journal of Clinical Endocrinology 20 238-252

Brannian JD, Griffin F, Papkoff H and Terranova PF (1988) Short and long phases of progesterone secretion during the oestrous cycle of the African elephant (Loxodonta africana) Joumal of Reproduction and Fertility 84 357-365

Bristol F (1986) Estrus synchronization in mares. In Current Therapy in Theriogenology 2: Diagnosis, Treatment and Prevention of Reproductive Diseases in Small and Large Animals, pp 661-664 Ed. DA Morrow. W B Saunders Company, Philadephia

Brown IL, Citino SC, Bush M, Lehnhardt J and Phillips LG (1991) Cyclic patterns of luteinizing hormone, follicle-stimulating hormone, inhibin, and progesterone secretion in the Asian elephant (Elephas maximus) Joumal of Zoo and Wildife Management 22 49-57

Butler GC and Marrian GF (1937) The isolation of pregnane-3,17,20-triol from the urine of women showing the adrenogenital syndrome Joumal of Biological Chemistry $119565-572$

Fotherby K (1960) Excretion of pregnanetriol during the normal menstrual cycle British Medical Journal 1 1545-1546

Gower DB and Honour JH (1984) Part 1. Steroid catabolism and urinary excretion. Part 2. Biliary excretion and enterohepatic circulation. In Steroid Biochemistry, pp 349-407 Ed. HJL Makin. Blackwell Scientific Publications, Oxford
Gross TS, Patton M, Armstrong DL and Simmons LG (1991) Estrus detection and synchronization in African elephants (Loxodonta africana): vaginal cytology and serum endocrine profiles Biology of Reproduction 44 (Supplement 1) Abstract 31

Hess DL, Schmidt AM and Schmidt MJ (1983) Reproductive cycle of the Asian elephant (Elephas maximus) in captivity Biology of Reproduction 28 767-773

Hindle JE, Möstl E and Hodges JK (1992) Measurement of urinary oestrogens and 20a-dihydroprogesterone during ovarian cycles of black (Diceros bicornis) and white (Ceratotherium simum) rhinoceroses Journal of Reproduction and Fertility 94 237-249

Hodges JK (1992) Detection of oestrous cycles and timing of ovulation Symposium of the Zoological Society of London 64 73-88

Hodges JK and Green DI (1989) A simplified enzymeimmunoassay for urinary pregnanediol-3-glucuronide: application to reproductive assessment in exotic species Journal of Zoology 219 89-99

Hodges JK, Bevan DJ, Celma M, Hearn JP, Jones DM, Kleiman DG, Knight JA and Moore HD (1984) Aspects of reproductive endocrinology of the female giant panda (Ailuropoda melanoleuca) in captivity with special reference to the detection of ovulation and pregnancy Journal of Zoology 203 253-267

Jainudeen MR, Eisenberg JF and Tilakeratne N (1971) Oestrous cycle of the Asian elephant, Elephas maximus, in captivity Joumal of Reproduction and Fertility 27 321-328

Kirkpatrick JF, Lasley BL and Schideler SE (1990) Urinary steroid evaluation to monitor ovarian function in exotic ungulates. VII. Urinary progesterone metabolites in the Equidae assessed by immunoassay Zoo Biology 9 341-348

Knox WM, Miller KV, Collins DC, Bush PB, Kiser TE and Marchinton RL (1992) Serum and urinary levels of reproductive hormones associated with the estrous cycle in white-tailed deer (Odocoileus virginianus) Zoo Biology 11 121-131

Liebermann S, Erlanger BF, Beiser SM and Agate FJ, Jr (1959) Steroid-protein conjugates: their chemistry, immunochemistry and endocrinological properties Recent Progress in Hormone Research 15 165-200

Loskutoff NM, Walker L, Ott-Joslin JE, Raphael BL and Lasley BL (1986) Urinary steroid evaluations to monitor ovarian function in exotic ungulates: II. Comparison between the giraffe (Giraffa camelopardalis) and the okapi (Okapia johnstoni) Zoo Biology 5 355-361

McDonald MF (1986) Estrous synchronization and control of the estrous cycle. In Current Therapy in Theriogenology 2: Diagnosis, Treatment and Prevention of Reproductive Diseases in Small and Large Animals pp 887-889 Ed. DA Morrow. WB Saunders Company, Philadelphia

Mainka SA and Lothrop CD, Jr (1990) Reproductive and hormonal changes during the estrous cycle and pregnancy in Asian elephants (Elephas maximus) Zoo Biology 9 411-419

Monfort SL, Jayaraman S, Schideler SE, Lasley BL and Hendrickx AG (1986) Monitoring ovulation and implantation in the cynomologus macaque (Macaca fascicularis) through evaluations of urinary estrone conjugates and progesterone metabolites: a technique for the routine evaluation of reproductive parameters Journal of Medical Primatology 15 17-26

Moss CJ (1983) Oestrous behaviour and female choice in the African elephant Behaviour 86 167-196

Pickett MT and Kellie AE (1962) Urinary excretion of pregnanetriol in the menstrual cycle. I. Additional evidence of identity Acta Endocrinologica 41 129-134

Pickett MT, Kyriakides EC, Stern MI and Sommerville IF (1959) Urinary pregnanetriol throughout the menstrual cycle: observations on a healthy subject and an adrenalectomised woman The Lancet 2 829-830

Plotka ED, Seal US, Zarembka FR, Simmons LG, Teare A, Phillips LG, Hinshaw KC and Wood DG (1988) Ovarian function in the elephant: luteinizing hormone and progesterone cycles in African and Asian elephants Biology of Reproduction 38 309-314

Poole JH, Kasman LH, Ramsay EC and Lasley BL (1984) Musth and urinary testosterone concentrations in the African elephant (Loxodonta africana) Journal of Reproduction and Fertility 70 255-260

Quilliam MA and Westmore JA (1980) Mass spectral studies of partial and mixed silyl derivatives of $5 \beta$ pregnane $3 \alpha, 17 \alpha, 20 \alpha$-triol European Journal of Mass Spectrometry, Biochemistry, Medical and Environmental Research $153-56$

Ramsey EC, Lasley BL and Stabenfeldt GH (1981) Monitoring the estrous cycle of the Asian elephant (Elephas maximus) using urinary estrogens American Journal of Veterinary Research 42 256-260

Samarajeewa $P$ and Kellie $A$ (1985) The radioimmunoassay of pregnanetriol 3a-glucuronide Journal of Steroid Biochemistry 22 843-849

Shackleton CHL, Honour JW, Dillon M and Milla P (1976) Multicomponent gas chromatographic analysis of urinary steroids excreted by an infant with a defect in aldosterone biosynthesis Acta Endocrinologica 81 762-769 
Shackleton CHL, Taylor NF and Honour JW (1980) An Atlas of Gas Chromatographic Profiles of Neutral Urinary Steroids in Health and Disease. Packard-Becker, Delft

Shaw HJ, Hillier GS and Hodges JK (1989) Developmental changes in luteinising hormone/human chorionic gonadotrophin. Steroidogenic responsiveness in marmoset granulosa cells: effects of follicle stimulating hormone and androgens Endocrinology 124 1669-1677

Short RV and London DR (1961) Defective biosynthesis of ovarian steroids in the Stein-Leventhal syndrome British Medical Joumal 1 1724-1727

Smith MC (1986) Synchronization of estrus and the use of implants and vaginal sponges. In Current Therapy in Theriogenology 2: Diagnosis, Treatment and Prevention of Reproductive Diseases in Small and Large Animals pp 582 Ed. DA Morrow. WB Saunders Company, Philadelphia
Smith RD (1986) Estrus detection. In Current Therapy in Theriogenology 2: Diagnosis, Treatment and Prevention of Reproductive Diseases in Small and Large Animals pp 153-157 Ed. DA Morrow. WB Saunders Company, Philadelphia

Taya K, Komura H, Kondoh M, Ogawa Y, Nakada K, Watanabe G, Sasamoto S, Tanabe K, Saito K, Tajima H and Narushima E (1991) Concentrations of progesterone, testosterone and estradiol- $17 \beta$ in the serum during the estrous cycle of Asian elephants (Elephas maximus) Zoo Biology 10 299-307

Walker LA, Cornell L, Dahl KD, Czekala NM, Dargen CM, Joseph B, Hsueh AJW and Lasley BL (1988) Urinary concentrations of ovarian steroid hormone metabolites and bioactive follicle-stimulating hormone in killer whales (Orcinus orchus) Biology of Reproduction 39 1013-1020

Zander J (1958) Steroids in the human ovary Joumal of Biological Chemistry 232 $117-122$ 